\title{
Exigência Protéica e Relação Energia/Proteína para Alevinos de Piracanjuba (Brycon orbignyanus) ${ }^{1}$
}

\author{
Marcelo Vinícius do Carmo e Sá ${ }^{2}$, Débora Machado Fracalossi ${ }^{3}$
}

\begin{abstract}
RESUMO - O objetivo do presente estudo foi determinar a exigência protéica e correspondente relação energia/proteína em dietas para alevinos de piracanjuba, Brycon orbignyanus. Seis dietas semi-purificadas isocalóricas foram formuladas para conter $3.000 \mathrm{kcal}$ de energia metabolizável (EM)/kg e concentrações de proteína bruta (PB) de 24, 26, 29, 32, 36 e 42\%. Para essas concentrações, as relações $\mathrm{E} / \mathrm{P}$ das dietas foram de 12,$3 ; 11,6 ; 10,4 ; 9,2 ; 8,5$ e 7,1 kcal EM/g PB, respectivamente. As fontes de proteína, lipídios e carboidratos digestíveis foram, respectivamente, caseína/gelatina, óleo de fígado de bacalhau/óleo de soja e dextrina. Após condicionamento de cinco dias, as dietas foram fornecidas, até a saciedade, em duas alimentações diárias, a 162 alevinos (27 peixes/dieta), que apresentaram $8,38 \pm 0,09 \mathrm{~g}$ de peso médio inicial, distribuídos em 18 tanques de fibra-de-vidro de $100 \mathrm{~L}$, conectados a um sistema de recirculação de água. A temperatura média da água foi de $26,3^{\circ} \mathrm{C}$, com extremos de 23,7 e $30,2^{\circ} \mathrm{C}$. Após 90 dias, a concentração de proteína na dieta que proporcionou ganho em peso máximo aos peixes foi $29 \% \mathrm{~PB}$, com relação E/P igual a 10,4 kcal EM/g PB. As dietas com concentrações de PB iguais a 32, 36 e 42\% não se mostraram superiores para conversão alimentar, taxa de eficiência protéica, valor produtivo da proteína e retenção de energia bruta. A deposição corporal de proteína e gordura não sofreu influência da concentração de PB da dieta.
\end{abstract}

Palavras-chave: Brycon orbignyanus, exigência protéica, piracanjuba, relação energia/proteína

\section{Dietary Protein Requirement and Energy to Protein Ratio for Piracanjuba (Brycon orbignyanus) Fingerlings}

\begin{abstract}
The aim of this study was to determine the dietary protein requirement and associated energy to protein (E/P) ratio for "Piracanjuba", Brycon orbignyanus, fingerlings. Casein-gelatin semipurified diets were formulated to contain six crude protein (CP) concentrations: 24, 26, 29, 32, 36 e 42\% at one energy level, 3,000 kcal metabolizable energy (ME)/kg. These diets resulted in E/P ratios of 12.3, 11.6, 10.4, 9.2, 8.5 and $7.1 \mathrm{kcal} \mathrm{ME} / \mathrm{g} \mathrm{CP}$, respectively. The protein, lipid and digestible carbohydrate sources were casein/gelatin, cod liver oil/soybean oil and dextrin, respectively. After an initial 5-day conditioning period, each experimental diet was fed to satiation, twice a day, to $8.38 \pm 0.09$ g piracanjuba fingerlings $(n=27)$, housed in eighteen 100-L fiberglass tanks connected to a water recirculating system, and kept at $26.3^{\circ} \mathrm{C}$ average water temperature (range: 23.7 to $30.2^{\circ} \mathrm{C}$ ). After 90 days, the lowest dietary CP level that produced maximum fish weight gain was $29 \% \mathrm{CP}$ with associated $\mathrm{E} / \mathrm{P}$ ratio of $10.4 \mathrm{kcal} \mathrm{ME} / \mathrm{g} \mathrm{CP}$. Higher dietary CP levels, i.e., 32,36 and $42 \%$ did not improve $29 \%$ CP feed conversion, protein efficiency ratio, apparent net protein utilization and gross energy retained. Wholebody fish composition (total lipid and protein concentration) was not affected by the dietary CP level.
\end{abstract}

Key Words: Brycon orbignyanus, energy to protein ratio, piracanjuba, protein requirement

\section{Introdução}

Como a proteína é o nutriente mais caro da dieta, é de grande importância determinar a concentração mínima desse nutriente que produz crescimento máximo nos animais (Clark et al., 1990). Contudo, é impraticável determinar, para uma dada espécie, um valor único de proteína dietética que sirva para todas as situações, porque muitos fatores influenciam essa exigência (Brown \& Robinson, 1989). Entre eles, destacam-se: temperatura da água, taxa de arraçoamento, tamanho do peixe, qualidade da proteína e participação de fontes energéticas nãoprotéicas (Robinson \& Wilson, 1985). Este último tem grande importância prática, uma vez que as concentrações de proteína e energia para peixes devem estar balanceadas para obtenção de crescimento ótimo, com elevadas taxas de eficiência alimentar e de retenção de proteína na carcaça (Ellis \& Reigh, 1991).

\footnotetext{
${ }^{1}$ Estudo desenvolvido durante o curso de Mestrado em Aqüicultura do primeiro autor (bolsista da CAPES), na Universidade Federal de Santa Catarina - UFSC.

2 Doutorando do Programa de Pós-Graduação em Zootecnia, Departamento de Melhoramento e Nutrição Animal/UNESP, campus de Botucatu/SP. E.mail: marcelosa@fca.unesp.br

3 Professor Adjunto, Departamento de Aqüicultura/Universidade Federal de Santa Catarina, Caixa postal 476, CEP: 88.040-900, Florianópolis/SC. E.mail: deboraf@cca.ufsc.br
} 
Deficiência ou excesso de energia digestível na dieta pode reduzir as taxas de crescimento dos peixes (NRC, 1993). Alta relação energia/proteína $(\mathrm{E} / \mathrm{P})$ da dieta, isto é, pouca proteína para muita energia, resulta na diminuição do consumo voluntário de alimento (Page \& Andrews, 1973). Com isso, haverá menor ingestão de proteína e de outros nutrientes essenciais, além de excessiva deposição de gordura visceral, reduzindo o rendimento de carcaça e o prazo de validade do produto final. Por outro lado, uma baixa relação E/P da dieta faz os peixes utilizarem grande parte da proteína como energia, encarecendo, dessa forma, a dieta (Lovell, 1989). Adicionalmente, proporciona, ainda, aumento na excreção de amônia para o meio, produzindo um efluente com maior potencial poluente (Kaushik \& Oliva-Teles, 1986).

A piracanjuba, Brycon orbignyanus, assim como outras espécies do gênero Brycon, é um peixe muito apreciado pelo valor e sabor de sua carne (Godoy, 1986). Trata-se de uma espécie nativa das bacias formadas pelos Rios Uruguai e Paraná, apresentando crescimento rápido, boa conversão alimentar, hábito alimentar onívoro e boa aceitação à ração artificial, quando em cativeiro (Cavalcanti, 1998).

Apesar de apresentar boas qualidades zootécnicas, ainda não existe tecnologia disponível para seu cultivo intensivo, havendo a necessidade de pesquisas para que se viabilize sua produção em larga escala. As exigências nutricionais elementares da piracanjuba, como as concentrações de proteína e energia na dieta, ainda não são conhecidas. Nesse sentido, Borghetti et al. (1991) concluíram que as dietas à base de farinha de peixe, com nível protéico de 35 e $40 \%$, foram satisfatórias para a criação intensiva de juvenis de piracanjuba, quando cultivados durante 145 dias em tanques-redes e alimentados com três dietas práticas isocalóricas (3.200 kcal EM/kg), contendo diferentes concentrações de proteína bruta (PB).

Já Carneiro et al. (1998), investigando o desempenho de alevinos de piracanjuba alimentados com dietas práticas que apresentavam diferentes proporções de proteína de origem animal $(0,1 / 4$ e $1 / 2$ da proteína da dieta) e quatro concentrações de PB (18, 24,30 e $36 \%$ ), observaram que a dieta contendo $30 \%$ de PB e $1 / 4$ de farinha de peixe apresentou os melhores resultados quanto a ganho em peso, conversão alimentar e taxa de eficiência protéica.

Como se observa, a concentração de PB exigida pela piracanjuba varia de 30 a $40 \%$ da dieta. Essa ampla variação está provavelmente associada às condições experimentais e composições das dietas práticas que foram utilizadas. Além disso, nos dois estudos anteriormente citados, não se determinou a relação E/P ótima das dietas.

O objetivo do presente estudo foi determinar a exigência protéica dietética de alevinos de piracanjuba, com base na relação $\mathrm{E} / \mathrm{P}$, para a concentração energética de $3.000 \mathrm{kcal} \mathrm{EM/kg}$.

\section{Material e Métodos}

Seis dietas experimentais, aproximadamente isocalóricas (3.000 kcal de EM/kg), com concentrações de PB de 24, 26, 29, 32, 36 e 42\%, foram formuladas a partir de ingredientes semi-purificados, apresentando relações EM/PB iguais a 12,3; 11,6; 10,$4 ; 9,2 ; 8,5$ e $7,1 \mathrm{kcal} / \mathrm{g}$, respectivamente (Tabela 1 ). Utilizou-se, como referência para a formulação das dietas, as exigências nutricionais para alevinos de bagre do canal, Ictalurus punctatus (NRC, 1993). A energia disponível foi estimada utilizando-se os "valores fisiológicos padrão" (VFP), isto é, $4 \mathrm{kcal} / \mathrm{g}$ para proteínas e carboidratos digestíveis e $9 \mathrm{kcal} / \mathrm{g}$ para lipídios (Lee \& Putnam, 1973; Shyong et al., 1998). Segundo Halver (1976), a energia das dietas estimada pelos VFP classifica-se como "metabolizável".

As dietas semi-purificadas apresentaram as mesmas proporções entre seus ingredientes, a saber: caseína/gelatina (2,3/1), óleo de soja/óleo de fígado de bacalhau (2/1) e dextrina/óleos $(6,7 / 1)$.

O delineamento experimental adotado foi o inteiramente casualizado, com seis tratamentos e três repetições. A designação das dietas para as unidades experimentais realizou-se mediante sorteio.

As dietas semi-purificadas foram preparadas misturando-se, inicialmente, os ingredientes secos para, em seguida, adicionarem-se os óleos e 30\% de água. A massa foi forçada através de uma matriz com orifícios de $2 \mathrm{~mm}$, sendo os filamentos acondicionados em sacos plásticos hermeticamente fechados e armazenados em freezer $\left(-18^{\circ} \mathrm{C}\right)$. No momento do arraçoamento dos peixes, os filamentos foram cortados manualmente para a formação dos péletes (Fracalossi et al., 1998).

Dezalevinos de piracanjuba (peso médio inicial $=$ 8,38 $\pm 0,09$ g), provenientes da Estação de Piscicultura de Volta Grande (CEMIG, Conceição da Alagoas, $\mathrm{MG})$, foram estocados em cada um dos 18 tanques retangulares de fibra-de-vidro $(0,7 \times 0,3 \times 0,5 \mathrm{~m})$, com 
Tabela 1 - Composição das dietas experimentais (\% na matéria seca)

Table 1 - Composition of the experimental diets (\% dry matter basis, \%)

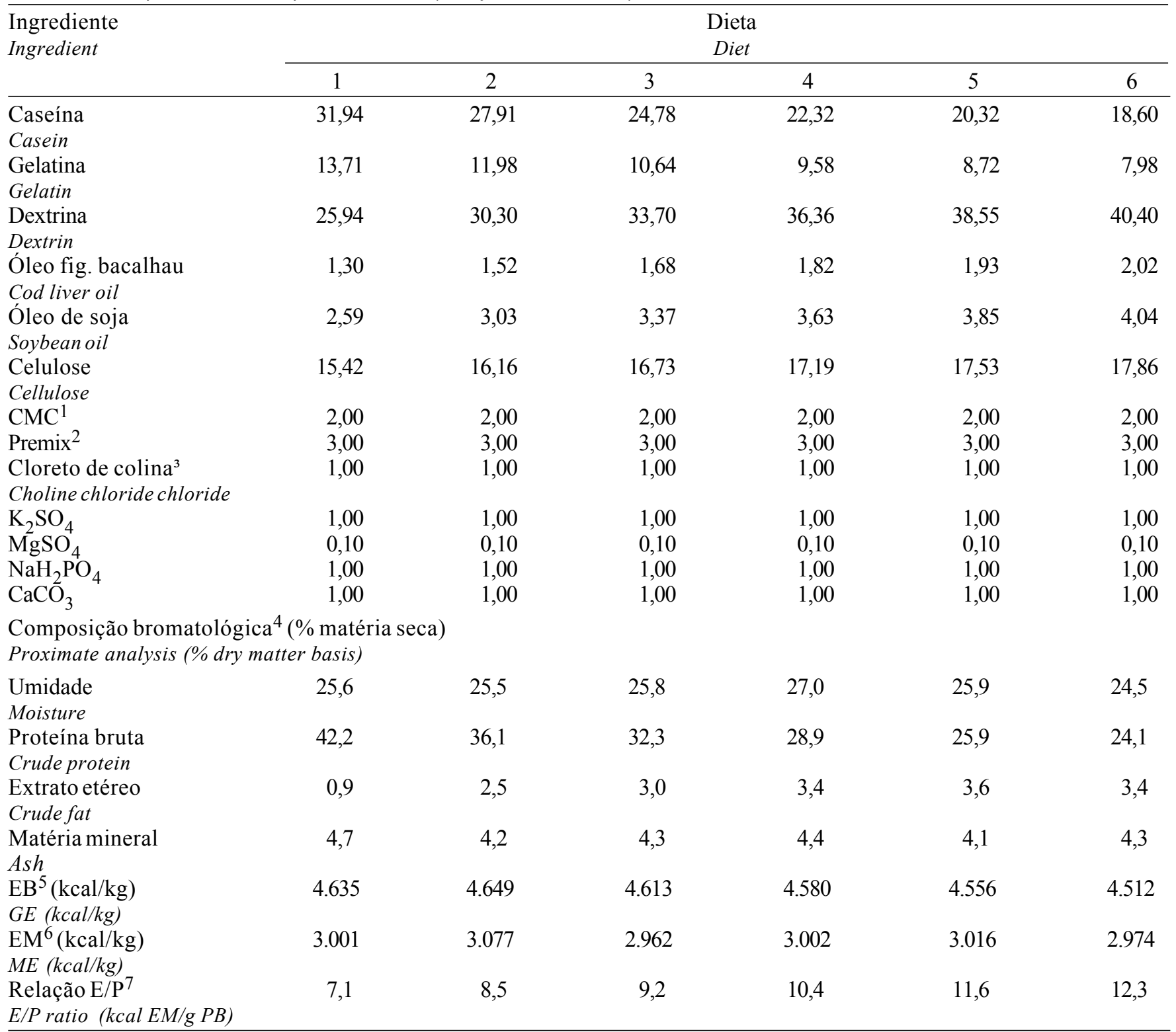

${ }^{1} \mathrm{CMC}=$ Carboximetil-celulose (Carboxymethyl-cellulose).

2 Composição do premix mineral-vitamínico [qtde/kg] (Mineral-vitamin premix composition per $\mathrm{kg}$ ): ácido fólico (folic acid) $250 \mathrm{mg}$, ácido pantotênico (pantothenic acid) $5.000 \mathrm{mg}$, biotina (biotin) $125 \mathrm{mg}$, niacina (niacin) $5.000 \mathrm{mg}$, vit. A $1.000 .000 \mathrm{UI}$, vit. $\mathrm{B}_{1} 1.250 \mathrm{mg}$, vit. $\mathrm{B}_{12} 3.750 \mathrm{mcg}$, vit. $B_{2} 2.500 \mathrm{mg}$, vit. $B_{6} 2.485 \mathrm{mg}$, vit. C $28.000 \mathrm{mg}$, vit. $\mathrm{D}_{3} 500.000 \mathrm{Ul}$, vit. E $20.000 \mathrm{Ul}$, vit. $\mathrm{K}_{3} 500$ mg; cobalto (cobalt) 25 mg, cobre (copper) , $2.000 \mathrm{mg}$, ferro (iron) $13.820 \mathrm{mg}$, iodo (iodine) $100 \mathrm{mg}$, manganês (manganese) $3.750 \mathrm{mg}$, selênio (selenium) $75 \mathrm{mg}$, e zinco (zinc) $17.499 \mathrm{mg}$.

3 Concentração de cloreto de colina por kg de dieta: $8,3 \mathrm{~g}$ (Choline chloride concentration per $\mathrm{kg}$ of diet: $8.3 \mathrm{~g}$ ).

${ }^{4}$ Média de duas repetições (Mean of two replicates).

5 Energia bruta (EB): calculada com a utilização dos valores médios de energia de combustão dos nutrientes (5,65 kcal/g PB; 9,40 kcal/g lipídio e 4,15 kcal/g de fibra e carboidrato) (Maynard et al., 1979) (Gross energy (GE): calculated from average heat of combustion values).

${ }^{6}$ Energia metabolizável (EM) estimada a partir dos valores fisiológicos padrões, i.e., $4 \mathrm{kcal} / \mathrm{g}$ para proteínas e carboidratos digestíveis; $9 \mathrm{kcal} / \mathrm{g}$ para lipídios (Lee \& Putnam, 1973; Shyong et al., 1998) (The metabolizable energy [ME] value of each diet was estimated based on the standard physiological fuel values, i.e., $4 \mathrm{kcal} / \mathrm{g}$ protein or digestible carbohydrates and $9 \mathrm{kcal} / \mathrm{g} \mathrm{lipid)}$.

7 Relação E/P = relação energia/proteína $(E / P$ ratio = energy/protein ratio; $k c a l M E / g C P)$. 
volume útil de 100 litros cada, componentes de um sistema de recirculação de água, situado no Laboratório de Nutrição de Espécies Aquáticas da Universidade Federal de Santa Catarina, Departamento de Aqüicultura, Florianópolis, SC. Tal sistema era servido por filtragem mecânica e biológica, vazão de água nos tanques experimentais de $0,7 \mathrm{~L} / \mathrm{min}$ e aeração contínua, através de difusores conectados a um soprador.

Fez-se um acompanhamento diário dos valores de temperatura e oxigênio dissolvido na água através de um oxímetro. Semanalmente, procedeu-se a determinação dos níveis de amônia total e nitrogênio de nitrito, por intermédio de kits colorimétricos para análise de água. Realizou-se também, semanalmente, a leitura do valor de $\mathrm{pH}$ da água, através de medidor eletrônico. A partir do $51^{\circ}$ dia do experimento, a água do sistema foi aquecida para evitar que a temperatura atingisse valores inferiores a $23^{\circ} \mathrm{C}$.

Não houve diferença significativa $(\mathrm{P}>0,05)$ entre as médias dos parâmetros de qualidade de água, estando as mesmas dentro dos limites para o desenvolvimento dos peixes tropicais de água doce (Boyd, 1990), Tabela 2.

O fotoperíodo foi de 12 horas de luz ( 7 às 19 h) e 12 horas de escuro, durante todo o experimento. A lâmpada fluorescente, responsável pela iluminação da sala, foi encoberta para diminuir a incidência direta de raios de luz nos tanques, objetivando-se, assim, controlar o canibalismo. Além dessa, outras providências foram tomadas, a saber: seleção inicial de indivíduos com peso homogêneo, fornecimento de abrigos para os peixes (cano de PVC $50 \mathrm{~mm}$ e $10 \mathrm{~cm}$ de comprimento) e alimentação até a saciedade. Ao final, a mortalidade total observada alcançou $10 \%$.

Tabela 2 - Parâmetros de qualidade de água Table 2 - Water quality parameters

\begin{tabular}{lcc}
\hline $\begin{array}{l}\text { Parâmetro } \\
\text { Parameter }\end{array}$ & $\begin{array}{c}\text { Média } \\
\text { Mean }\end{array}$ & $\begin{array}{c}\text { Faixa de variação } \\
\text { Range }\end{array}$ \\
\hline $\begin{array}{l}\text { Temperatura }\left({ }^{\circ} \mathrm{C}\right) \\
\text { Temperature }\end{array}$ & 26,3 & $23,7-30,2$ \\
$\begin{array}{l}\text { Oxigênio dissolvido (mg/L) } \\
\text { Dissolved oxygen }\end{array}$ & 6,83 & $4,73-9,73$ \\
$\begin{array}{l}\text { Saturação de oxigênio (\%) } \\
\text { Oxygen saturation } \\
\text { pH }\end{array}$ & 85,8 & $66,8-98,5$ \\
$\begin{array}{l}\text { Amônia total (mg/L) } \\
\text { Total ammonia }\end{array}$ & - & $5,17-6,75$ \\
N-nitrito $(\mathrm{mg} / \mathrm{L})$ & 0,09 & $0,00-0,25$ \\
\hline
\end{tabular}

Uma semana antes do início do experimento, efetuou-se o condicionamento dos alevinos às dietas semi-purificadas. Os animais receberam proporções crescentes de uma dieta basal semi-purificada, misturada a proporções decrescentes de uma dieta comercial extrusada contendo $22 \% \mathrm{~PB}$, que já vinha sendo fornecida. A fórmula da dieta basal é a mesma apresentada pelo NRC (1993) como dieta semipurificada de referência para o bagre do canal, acrescida de sais minerais (sulfatos de potássio e de magnésio, fosfato monosódico e carbonato de cálcio) e cloreto de colina. Apresentava $26 \%$ umidade, $37 \% \mathrm{~PB}, 6 \%$ lipídios totais (\% na matéria seca), $3.570 \mathrm{kcal} \mathrm{EM} / \mathrm{kg}$ e 9,6 kcal EM/g PB (NRC, 1993). Durante esse período, a ração diária foi fornecida a uma taxa de 3\% da biomassa total existente em cada tanque, em três refeições: às 9,14 e 19 h. Ao final de cinco dias, os peixes aceitavam a dieta basal semi-purificada.

No início da fase experimental, retirou-se um alevino de cada tanque para a realização das análises de composição corporal (proteína bruta, extrato etéreo, cinzas e energia bruta) (AOAC, 1984), agrupando-os numa amostra única. Os alevinos foram sacrificados através de $200 \mathrm{mg} / \mathrm{L}$ do anestésico tricaína metanosulfonato (MS-222).

Os remanescentes (nove alevinos/tanque) foram pesados coletivamente, apresentando uma biomassa inicial média igual a 75,4 $\pm 1,0 \mathrm{~g} /$ tanque. Não houve diferença significativa entre as biomassas iniciais para os diferentes tratamentos $(\mathrm{P}>0,05)$.

A partir do $2^{\circ}$ dia da fase experimental, os alevinos receberam, por 90 dias, as rações experimentais, em duas refeições diárias, às 9 e 17 h, até a saciedade. A quantidade de dieta consumida, em cada um dos tanques, fora devidamente registrada. No dia anterior ao da realização das pesagens, realizadas a cada duas semanas, o arraçoamento era suspenso para não interferir nos resultados. Na realização das biometrias, os peixes eram sedados numa solução de $70 \mathrm{mg} / \mathrm{L}$ de MS-222, por dois minutos. Após cada pesagem, eles eram tratados profilaticamente com uma solução de $20 \mathrm{~g} / \mathrm{L}$ de sal, durante um minuto. Ao final do período experimental, os peixes foram sacrificados (21 peixes/tratamento) para a realização de novas análises de composição corporal total (os mesmos parâmetros medidos durante as análises iniciais).

As seguintes variáveis foram determinadas para a avaliação das diferentes dietas: Ganho em Peso Diário (GPD) [(biomassa final - biomassa inicial $/ \mathrm{n}^{\mathrm{o}}$ 
peixes) $/ \mathrm{n}^{0}$ dias do período], Conversão Alimentar (CA) [quantidade de alimento seco consumido, corrigida para $10 \%$ de umidade/ganho em peso úmido], Taxa de Eficiência Protéica (TEP) [ganho em peso úmido/proteína consumida], Valor Produtivo da Proteína (VPP) [(proteína corporal final - proteína corporal inicial)/proteína consumida $x$ 100] e Retenção de Energia Bruta (REB) [(energia corporal final - energia corporal inicial)/energia consumida $\mathrm{x} 100]$.

Os dados obtidos foram submetidos à análise de variância (ANOVA) e, quando houve diferença significativa entre os tratamentos, foram comparados por meio teste de Tukey, utilizando-se o software "SigmaStat for Windows 2.0". Aplicou-se, ainda, análise de regressão não-linear para se avaliar o efeito da concentração de $\mathrm{PB}$ da dieta sobre o ganho em peso dos peixes, segundo o método proposto por Robbins et al. (1979), valendo-se do software "CurveExpert 1.34". Adotou-se o nível de significância de $5 \%$ em todos os testes empregados.

\section{Resultados e Discussão}

Os resultados desse estudo estão sumarizados na Tabela 3. O menor ganho em peso diário (GPD) dos peixes $(0,17 \mathrm{~g} /$ peixe/dia $)$ foi o referente à dieta com $24 \%$ PB e $12,3 \mathrm{kcal}$ EM/g PB. A dieta com $26 \%$ PB e 11,6 kcal EM/g PB produziu uma melhora nesse parâmetro $(0,20 \mathrm{~g} /$ peixe/dia $)$, sendo esse resultado, contudo, estatisticamente igual ao anterior $(\mathrm{P}>0,05)$. A dieta com $29 \%$ PB e 10,4 kcal EM/g PB resultou em um aumento significativo $(\mathrm{P}<0,05)$ no GPD, sendo o mesmo igual a $0,26 \mathrm{~g} / \mathrm{peixe} / \mathrm{dia}$. A partir daí, incrementos adicionais de $\mathrm{PB}$ não produziram melhora no GPD dos peixes, havendo estabilização nesse índice. Portanto, a exigência dietética dessa espécie por aminoácidos necessários ao seu crescimento máximo foi atendida com essa dieta e, além dessa concentração de $\mathrm{PB}$, a proteína excedente nas dietas com 32, 36 e 42\% PB, correspondendo a acréscimos de 3, 7 e $13 \% \mathrm{~PB}$, respectivamente, estava sendo, provavelmente, metabolizada para produção de energia. Essas

Tabela 3 - Efeito da concentração de proteína bruta (PB) e da relação energia/proteína (E/P) da dieta sobre os parâmetros de crescimento e eficiência alimentar

Table 3 - Effect of dietary crude protein (CP) level and energy to protein (E/P) ratio on growth and feed efficiency parameters

\begin{tabular}{|c|c|c|c|c|c|c|}
\hline \multirow[t]{2}{*}{$\begin{array}{l}\text { Parâmetro } \\
\text { Parameter }\end{array}$} & \multicolumn{6}{|c|}{$\begin{array}{c}\text { Concentração de proteína bruta da dieta (\%) } \\
\text { Dietary crude protein levels } \\
\text { Relação E/P da dieta em kcal EM } \mathrm{EM}^{3} / \mathrm{g} \mathrm{PB} \\
\text { Dietary E/P ratio, } k \text { cal } M E / g C P\end{array}$} \\
\hline & $\begin{array}{c}24 \\
(12,3)\end{array}$ & $\begin{array}{c}26 \\
(11,6)\end{array}$ & $\begin{array}{c}29 \\
(10,4)\end{array}$ & $\begin{array}{c}32 \\
(9,2)\end{array}$ & $\begin{array}{c}36 \\
(8,5)\end{array}$ & $\begin{array}{c}42 \\
(7,1)\end{array}$ \\
\hline $\begin{array}{l}\text { Peso inicial (g) } \\
\text { Initial weight }\end{array}$ & $8,02^{a} \pm 0,55$ & $8,14^{\mathrm{a}} \pm 0,24$ & $8,55^{\mathrm{a}} \pm 0,16$ & $8,62^{\mathrm{a}} \pm 0,08$ & $8,62^{\mathrm{a}} \pm 0,21$ & $8,55^{\mathrm{a}} \pm 0,10$ \\
\hline $\begin{array}{l}\mathrm{GPD}^{4}(\mathrm{~g} / \mathrm{peixe} / \mathrm{dia}) \\
\text { g/fish/day }\end{array}$ & $0,17^{b} \pm 0,01$ & $0,20^{\mathrm{ab}_{ \pm 0}}, 02$ & $0,26^{\mathrm{a}} \pm 0,01$ & $0,24^{\mathrm{ab}_{ \pm}}+0,02$ & $0,26^{a} \pm 0,03$ & $0,26^{\mathrm{a}} \pm 0,01$ \\
\hline $\begin{array}{l}\mathrm{CA}^{5} \\
F C R\end{array}$ & $1,76^{\mathrm{b}} \pm 0,05$ & $1,63^{a b} \pm 0,20$ & $1,55^{\mathrm{ab}_{ \pm}}+0,02$ & $1,48^{a b} \pm 0,21$ & $1,06^{\mathrm{a}} \pm 0,08$ & $1,22^{\mathrm{ab}} \pm 0,08$ \\
\hline $\begin{array}{l}\text { TEP }^{6} \\
P E R\end{array}$ & $2,53^{\mathrm{a}} \pm 0,08$ & $2,64^{\mathrm{a}} \pm 0,31$ & $2,48^{a} \pm 0,04$ & $2,47^{a_{1}} \pm 0,44$ & $2,95^{\mathrm{a}} \pm 0,24$ & $2,17^{a} \pm 0,16$ \\
\hline $\begin{array}{l}\operatorname{VPP}(\%)^{7} \\
A N P U\end{array}$ & $38,98^{\mathrm{a}} \pm 1,01$ & $41,12^{\mathrm{a}_{ \pm}}+10$ & $40,94^{\mathrm{a}} \pm 1,25$ & $40,53^{a} \pm 7,33$ & $49,88^{\mathrm{a}} \pm 5,02$ & $37,74^{\mathrm{a}} \pm 3,20$ \\
\hline $\begin{array}{l}\operatorname{REB}(\%)^{8} \\
\text { Gross energy retained }\end{array}$ & $15,59^{b} \pm 0,89$ & $17,75^{\mathrm{ab}_{ \pm}, 11}$ & $17,80^{\mathrm{ab}} \pm 0,15$ & $19,87^{\mathrm{ab}} \pm 3,58$ & $26,81^{\mathrm{a}} \pm 1,89$ & $22,51^{a b} \pm 1,57$ \\
\hline $\begin{array}{l}{ }^{1} \text { Média de três repetiçõ } \\
2 \text { Valores de uma mesma } \\
\text { by different letters are sig } \\
3 \text { EM = energia metaboliz } \\
{ }^{4} \text { Ganho em peso diário } \\
{ }^{5} \text { CA [Conversão alimen } \\
{ }^{*} \mathrm{~A} \text { umidade do aliment } \\
{ }^{6} \text { TEP [Taxa de eficiênci } \\
{ }^{7} \text { VPP [Valor produtiva do } \\
=\text { final body protein - initia } \\
{ }^{8} \text { REB [Retenção de ener }\end{array}$ & $\begin{array}{l}\text { o-padrão da m } \\
\text { ue não compar } \\
y \text { different at } P<. C \\
E=\text { metabolizable } \\
\text { eight gain). } \\
\text { limento seco* }{ }^{*} \\
\text { rrigida para } 10 \\
\text { ca] = ganho en } \\
\text { la] = proteína cc } \\
\text { rotein/total protei } \\
\text { a] = energia cor }\end{array}$ & $\begin{array}{l}\text { (Mean of three I } \\
\text { m uma mesma } \\
\text { gy). } \\
\text { umido/ganho e } \\
\text { ood water conter } \\
\text { so úmido/prote } \\
\text { ral final - proteí } \\
\text { ke } x 100) \text {. } \\
\text { al final - energie }\end{array}$ & $\begin{array}{l}\text { ates } \pm \text { standard e } \\
\text { são estatisticar } \\
\text { eso úmido. (FCF } \\
\text { rected to } 10 \%) \text {. } \\
\text { onsumida. (PEF } \\
\text { rporal inicial x } 1\end{array}$ & $\begin{array}{l}\text { d conversion ra } \\
\text { tein efficiency } r \\
\text { oteína consur }\end{array}$ & $\begin{array}{l}\text { (Values withir } \\
\text { dry food intake/ } \\
\text { weight gain/prc } \\
\text { ANPU [Appare }\end{array}$ & $\begin{array}{l}\text { me row followed } \\
\text { veight increase). } \\
\text { take). } \\
\text { rotein utilization] }\end{array}$ \\
\hline
\end{tabular}


observações estão de acordo com os resultados da análise de regressão calculada entre as concentrações de PB da dieta e os valores de GPD dos peixes, indicando que os alevinos de piracanjuba têm sua exigência protéica atendida quando alimentados com uma dieta contendo $29 \%$ PB e $10,4 \mathrm{kcal} \mathrm{EM} / \mathrm{g}$ PB (Figura 1).

Para o cálculo da exigência protéica, adotou-se o método preconizado por Robbins et al. (1979), segundo o qual "a exigência nutricional é definida pelo ponto sobre a abscissa (nutriente sob análise) que corresponde a $95 \%$ do valor da assíntota superior que toca a ordenada (ganho em peso) e que foi obtida a partir de uma curva exponencial ajustada aos dados experimentais." Dentre os vários modelos de curvas exponenciais existentes, escolheu-se o modelo $\operatorname{logístico~}\left(\mathrm{y}=\mathrm{a} / 1+\mathrm{b} e^{-\mathrm{cx}}\right)$ por ser o que melhor se ajustou aos dados experimentais $\left(\mathrm{R}^{2}=0,92\right)$. A equação resultante da regressão não-linear calculada foi igual a $y=0,26 /\left(1+53 \cdot 138,35 e^{-0,48 x}\right)$. Utilizando-se o valor de 0,25 para ganho em peso (equivalente a $95 \%$ da assíntota superior), obtém-se um valor estimado para concentração de $\mathrm{PB}$ da dieta igual a $29,0 \%$, valor sugerido para exigência protéica.

Ressalta-se, contudo, que se elevando a concentração energética da dieta ( $>3.000 \mathrm{kcal} \mathrm{EM} / \mathrm{kg}$ ), existe a possibilidade de se reduzir o valor de PB exigido, já que, em níveis energéticos inadequados, parte da proteína será usada como fonte energética

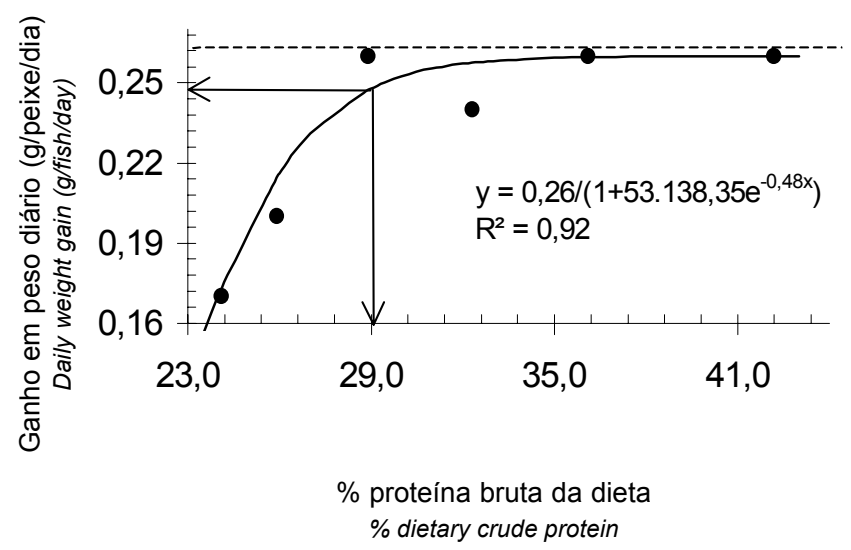

Figura 1 - Relação entre a concentração de proteína bruta (PB) da dieta e o ganho em peso diário de alevinos de piracanjuba. Vinte e nove por cento de PB corresponde ao ponto de exigência protéica.

Figure 1 - Correlation between dietary crude protein (CP) concentration and pirancanjuba fingerlings daily weight gain. Twenty-nine per cent CP represents the protein requirement.
(Cowey \& Sargent, 1979). Uma vez feita essa verificação, determinar-se-á, finalmente, o valor de "exigência protéica" e "relação energia/proteína ótima" da dieta (El-Sayed \& Teshima, 1992). Além disso, o valor de exigência protéica encontrado no presente trabalho, isto é, $29 \% \mathrm{~PB}$ e 10,4 kcal EM/g PB, somente é válido para dietas cujas fontes protéicas apresentem a mesma qualidade (digestibilidade e perfil de aminoácidos essenciais) das proteínas utilizadas nesse estudo (caseína e gelatina), fontes protéicas de excelente qualidade (Henken et al., 1986). Isso porque a exigência protéica dos peixes se altera com a qualidade da proteína empregada na dieta (Garling \& Wilson, 1976). Assim, por conta da digestibilidade inferior de ingredientes como farinha de peixe e farelo de soja, quando comparados às fontes semi-purificadas (Shiau \& Lan, 1996), provavelmente deva-se incluir, na formulação de dietas práticas para alevinos de piracanjuba, mais de $29 \%$ $\mathrm{PB}$, para se obter ganho máximo em peso. Apesar disso, por considerar que a relação E:P ótima da dieta é um parâmetro mais constante que a exigência protéica, sugere-se que um valor em torno de 10,4 kcal EM/g PB, seja o melhor balanceamento de uma dieta prática para alevinos de piracanjuba.

À medida que se elevou a concentração de PB da dieta, houve melhora na conversão alimentar (CA), não havendo, contudo, diferença significativa entre os tratamentos, salvo pela comparação entre as dietas com $36 \%$ PB e $8,5 \mathrm{kcal} \mathrm{EM} / \mathrm{g}$ PB e com $24 \%$ PB e 12,3 $\mathrm{kcal} \mathrm{EM} / \mathrm{g} \mathrm{PB}$. Os peixes alimentados com a dieta que continha $42 \% \mathrm{~PB}$ e $7,1 \mathrm{kcal} \mathrm{EM} / \mathrm{g}$ PB foram incapazes de converter o alimento recebido em ganho em peso de forma mais eficiente que aqueles que receberam a dieta com 29\% PB e 10,4 kcal EM/g PB. Provavelmente, a parcela de $\mathrm{PB}$ excedente a $29 \%$ foi empregada para produção de energia, explicando a pior CA.

A taxa de eficiência protéica (TEP), que indica quanto da PB da dieta foi convertida em peso corporal, não foi significativamente diferente $(\mathrm{P}>0,05)$ entre as diferentes concentrações protéicas das dietas, não apresentando, também, tendência de comportamento clara, como a observada por Mazid et al. (1979), para Tilapia zillii; por Siddiqui et al. (1988), para tilápia do Nilo, Oreochromis niloticus, e por Serrano et al. (1992), para corvina vermelha, Sciaenops ocellatus, em que a TEP foi máxima nos tratamentos com menor concentração protéica, decrescendo à medida que a $\mathrm{PB}$ da dieta aumentava. Contudo, os resultados do presente trabalho estão de 
acordo com os apresentados por De Silva \& Perera (1985) para tilápia do Nilo e por Jantrarotai et al. (1998) para o bagre africano híbrido, Clarias macrocephalus $x$ C. gariepinus, que verificaram que a TEP não foi afetada pelo teor de PB da dieta fornecida aos alevinos dessas espécies. Em média, esse parâmetro foi igual a 2,54 para os seis tratamentos experimentais, significando que, para cada 1grama de PB consumida, houve um ganho em peso médio igual a 2,54 gramas.

Da mesma forma, o valor produtivo da proteína (VPP), que indica quanto da PB consumida na dieta foi convertida em PB corporal, não foi significativamente diferente $(\mathrm{P}>0,05)$ para as diferentes concentrações protéicas das dietas, sendo, em média, igual a 41,5\%. Para cada 1 grama de PB consumida na dieta, houve um incremento médio de $0,41 \mathrm{~g}$ de $\mathrm{PB}$ no corpo dos peixes e, desse modo, 0,59 g de $\mathrm{PB} / \mathrm{g}$ PB consumida foram utilizadas para produção de energia, deposição de gordura e/ou foram parcialmente excretadas juntamente com as fezes. No presente trabalho, não se observou, para esse parâmetro de eficiência protéica, resultados tão claros como os obtidos por Dabrowski (1977), com carpas capim, Ctenopharyngodon idella, e por Shiau \& Huang (1989) com tilápias híbridas, Oreochromis niloticus x O. aureus, em que houve diminuição na deposição de proteína na carcaça dos animais com o aumento na concentração de PB da dieta. Entretanto, pode-se notar que, exceto pelo resultado de VPP da dieta com $36 \%$ PB e 8,5 kcal EM/g PB, houve tendência de queda nesse índice de eficiência protéica nas dietas com mais de $29 \%$ PB e $10,4 \mathrm{kcal}$ $\mathrm{EM} / \mathrm{g}$ PB. Uma possível explicação para isso é a diminuição da energia disponível para a realização da síntese protéica, por conta da elevação dos gastos energéticos e do incremento calórico (perdas energéticas na forma de calor), associados com o trabalho de desaminação da proteína em excesso nas dietas (Jauncey, 1982; Cho \& Kaushik, 1985).

A retenção de energia bruta (REB) indica quanto da energia bruta presente na dieta é convertida em energia bruta corporal. No presente estudo, não houve diferença significativa $(\mathrm{P}>0,05)$, em relação à $\mathrm{REB}$, entre as dietas experimentais, exceto entre a dieta com 24\% (menor REB) e 36\% PB (maior REB) (Tabela 3). Notou-se, ainda, que houve tendência de elevação na REB com o aumento na concentração de PB da dieta, assim como verificado por Jantrarotai et al. (1998), em alevinos de bagre africano híbrido.

Entre as variáveis analisadas no presente estudo, o
GPD foi a mais sensível à variação na concentração de PB da dieta, apresentando, com maior clareza, o ponto de exigência protéica. O mesmo foi observado por Moore et al. (1988) com alevinos de esturjão branco, Acipenser transmontanus. Segundo Cowey (1992), diferentemente do que acontece com a nutrição de animais terrestres, a CA, bem como outras variáveis que envolvam consumo alimentar, tais como: TEP, VPP e REB, não deve ser usada como o principal critério para se estabelecer a exigência nutricional em experimentos com peixes, devido à dificuldade de se medir, com precisão, o consumo alimentar dos mesmos. Esse autor sugere que o GPD é o parâmetro mais adequado para indicar a exigência protéica.

Apesar de as diferenças entre os resultados da composição corporal dos alevinos que receberam as dietas com diferentes concentrações protéicas serem pequenas e não significativas $(\mathrm{P}>0,05)$, pode-se perceber que, à medida que se aumentou a concentração de proteína da dieta, houve tendência de aumento da concentração de PB corporal e diminuição da concentração de lipídios totais (extrato etéreo) (Tabela 4). Outros estudos, não obstante terem empregado dietas com concentrações protéicas bem distintas, também não encontraram diferenças significativas entre os resultados de composição corporal. Isso foi observado em pós-larvas de carpa cabeça grande, Aristichthys nobilis (Santiago \& Reyes, 1991), em alevinos de T. zillii (Mazid et al., 1979), de tilápia azul, Oreochromis aureus (Winfree \& Stickney, 1981), e de corvina vermelha, S. ocellatus (Serrano et al., 1992).

$\mathrm{O}$ valor da relação $\mathrm{E} / \mathrm{P}$ da dieta, que resultou em ganho em peso máximo com um mínimo de $\mathrm{PB}(10,4 \mathrm{kcal}$ EM/g PB), está um pouco acima daquele encontrado para carpa comum, Cyprinus carpio, de 9,3 kcal ED/g proteína digestível (PD) (Takeuchi et al., 1979), para tilápia azul, 9,4 kcal ED/g PB (Winfree \& Stickney, 1981), para tilápia do Nilo, 9,7 kcal ED/g PD (NRC, 1993), para tainha cinzenta, Chelon labrosus, 9,8 kcal ED/g PB (Ojaveer et al., 1996) e para carpa capim, 10,0 kcal ED/g PB (Ding, 1991). Entretanto, está abaixo da relação E/P ótima encontrada para o bagre do canal, 11,4 kcal EM/g PB (Garling \& Wilson, 1976). No entanto, pelo fato de a energia disponível das dietas utilizadas no presente trabalho ter sido estimada a partir dos valores fisiológicos padrão (Stickney, 1994), existe a possibilidade de ter havido, apesar da utilização de ingredientes semipurificados, uma superestimativa nesse valor (3.000 kcal EM/kg). Dessa forma, sugere-se que, no 
momento em que se conheça a digestibilidade dos ingredientes utilizados nesse estudo para alevinos de piracanjuba, haverá uma correção para baixo no valor da melhor relação E/P encontrada, devendo ficar compreendida entre 9-10 kcal energia digestível/g PB. Esse intervalo, sugerido por Hardy \& Masumoto (1991), foi calculado a partir das informações de exigências protéicas e energéticas em dietas para o bagre do canal, truta arco-íris, salmão do Pacífico, carpa comum e tilápia, apresentadas pelo NRC (1993).

Apesar da dificuldade existente para a comparação direta das exigências protéicas encontradas para diferentes espécies de peixes ser complicada pelas diferenças existentes nos tamanhos do peixes, nas formulações das dietas e nas condições de cultivo empregadas (Lochmann \& Phillips, 1994), pode-se observar, na Tabela 5, que a exigência protéica para peixes onívoros varia de 24 a $37 \%$ PB. Os alevinos de piracanjuba, no presente trabalho, apresentaram exigência proteína similar à encontrada pela maioria dos estudos realizados com o objetivo de definir a exigência protéica de outras espécies onívoras (Tabela 5).

Tabela 4 - Efeito da concentração de proteína bruta (PB) e da relação energia/proteína (E/P) da dieta sobre a composição corporal de alevinos de piracanjuba (\% na matéria seca)

Table 4 - Effect of dietary crude protein (CP) level and energy to protein ratio on piracanjuba fingerlings body composition (dry weight basis, \%)

\begin{tabular}{|c|c|c|c|c|c|c|c|}
\hline$\%$ & $\begin{array}{l}\text { Inicial } \\
\text { Initial }\end{array}$ & \multicolumn{5}{|c|}{$\begin{array}{c}\text { Concentração de proteína bruta da dieta }(\%)^{1} \\
\text { Dietary crude protein level } \\
\left.\text { (Relação E/P da dieta em } \mathrm{kcal} \mathrm{EM}^{2} / \mathrm{g} \mathrm{PB}\right) \\
\text { Dietary E/P ratio }(k c a l M E / g C P)\end{array}$} & $\begin{array}{c}42 \\
(7,1) \\
\end{array}$ \\
\hline $\begin{array}{l}\mathrm{PB}^{3} \\
C P\end{array}$ & 67,10 & $56,97^{\mathrm{a}} \pm 0,64$ & $56,83^{a} \pm 0,13$ & $58,17^{\mathrm{a}} \pm 1,13$ & $58,13^{a} \pm 0,26$ & $59,03^{a} \pm 1,33$ & $60,23^{a} \pm 0,67$ \\
\hline
\end{tabular}

${ }^{1}$ Média de três repetições \pm erro-padrão da média (Mean of three replicates \pm standard error of mean).

${ }^{2}$ EM (energia metabolizável) (ME metabolizable energy).

${ }^{3}$ Valores de uma mesma linha que não compartilham uma mesma letra são estatisticamente diferentes $(P<0,05)($ Values within the same row which bear different letters are significantly different at $P<.05)$.

${ }^{4}$ Extrato etéreo (Ether extract).

Tabela 5 - Exigência protéica em dietas para peixes onívoros cultivados

Table 5 - Dietary protein requirement for omnivorous cultivated fishes

\begin{tabular}{|c|c|c|c|}
\hline $\begin{array}{l}\text { Espécie } \\
\text { Specie }\end{array}$ & $\begin{array}{l}\text { Exigência protéica }(\% \mathrm{~PB}) \\
\text { Protein requirement }(\% \mathrm{CP})\end{array}$ & $\begin{array}{l}\text { Peso inicial }(\mathrm{g}) \\
\text { Initial weight }\end{array}$ & $\begin{array}{l}\text { Referência } \\
\text { Reference }\end{array}$ \\
\hline Tambaqui (Colossoma macropomum) & $\begin{array}{l}24 \\
30 \\
37\end{array}$ & $\begin{array}{r}30,2 \\
30,0 \\
5,0\end{array}$ & $\begin{array}{l}\text { Camargo et al. (1998) } \\
\text { Merola \& Cantelmo (1987) } \\
\text { Eckmann (1987) }\end{array}$ \\
\hline Pacu (Piaractus mesopotamicus) & $\begin{array}{l}26 \\
30 \\
36\end{array}$ & $\begin{array}{r}7,9 \\
28,0 \\
22,2\end{array}$ & $\begin{array}{l}\text { Fernandes }(1998) \\
\text { Carneiro }(1990) \\
\text { Brener }(1988)\end{array}$ \\
\hline $\begin{array}{l}\text { Bagre do canal (Ictalurus punctatus) } \\
\text { "Goldfish" (Carassius auratus) } \\
\text { Piracanjuba (Brycon orbignyanus) } \\
\text { Tilápia do Nilo (Oreochromis niloticus) } \\
\text { Pirapitinga (Piaractus brachypomus) } \\
\text { Bagre africano híbrido } \\
\text { Clarias macrocephalus x C. gariepinus }\end{array}$ & $\begin{array}{l}24 \\
29 \\
29 \\
30 \\
30 \\
35\end{array}$ & $\begin{array}{r}6,8 \\
0,1 \\
8,4 \\
40,0 \\
179,4 \\
2,0-4,0\end{array}$ & $\begin{array}{l}\text { Garling \& Wilson (1976) } \\
\text { Lochmann \& Phillips (1994) } \\
\text { (presente trabalho) } \\
\text { Siddiqui et al. (1988) } \\
\text { Gutierrez et al.(1996) } \\
\text { Jantrarotai et al. (1998) }\end{array}$ \\
\hline
\end{tabular}




\section{Conclusões}

Os resultados desse estudo indicaram que, dentro da concentração energética de $3.000 \mathrm{kcal} \mathrm{EM} / \mathrm{kg}$, a dieta semi-purificada contendo a menor concentração de proteína bruta, resultante em ganho em peso máximo de alevinos de piracanjuba, foi aquela com $29 \%$ PB e $10,4 \mathrm{kcal} \mathrm{EM} / \mathrm{g} \mathrm{PB}$. As dietas com concentrações de PB acima de $29 \%$ não se mostraram superiores em termos de conversão alimentar, taxa de eficiência protéica, valor produtivo da proteína e retenção de energia bruta que a primeira. A qualidade corporal dos peixes, com relação à proteína e gordura depositadas nos mesmos, não sofreu influência da concentração de PB da dieta.

\section{Agradecimento}

À Estação de Piscicultura de Volta Grande (CEMIG), Conceição das Alagoas, Minas Gerais, pela doação dos alevinos; ao Dr. Alex Pires de Oliveira Nuñer (Departamento de Aqüicultura, CCA/ UFSC), por suas valiosas sugestões e comentários durante o planejamento, execução e redação do presente trabalho; ao Dr. Evoy Zaniboni Filho (Departamento de Aqüicultura, CCA/UFSC) e demais membros do Laboratório de Biologia e Cultivo de Peixes de Água Doce (LAPAD/Depto. Aqüicultura/UFSC), pelo apoio operacional e logístico prestados durante a realização do experimento e, em especial, ao acadêmico do curso de Biologia (CCB/UFSC), Raphael de Leão Serafini, pela colaboração na montagem do sistema de tanques e de recirculação de água.

\section{Literatura Citada}

ASSOCIATION OF OFFICIAL ANALITICAL CHEMISTS AOAC. Official methods of analysis. 14.ed. Arlington: 1984. 1141p.

BORGHETTI, J.R.; CANZI, C.; NOGUEIRA, S.V.G. A influência da proteína no crescimento do matrinchã (Brycon orbignyanus) ( $\mathrm{sic}$ ) criado em tanques-rede. Revista Brasileira de Biologia, v.51, n.3 p.695-699, 1991.

BOYD, C. Water quality in ponds for aquaculture. Alabama: Birmingham Publishing, 1990. 482p.

BRENER, M. Determinação da exigência de proteína do pacu (Colossoma mitrei, Berg, 1895). Viçosa, MG: Universidade Federal de Viçosa, 1988. Dissertação (Mestrado em Zootecnia) - Universidade Federal de Viçosa, 1988.

BROWN, P.B.; ROBINSON, E.H. Comparison of practical catfish feeds containin 26 or $30 \%$ protein. Progressive FishCulturist, v.51, p.149-151, 1989.
CAMARGO, A.C.S.; VIDAL Jr., M.V.; DONZELE, J.L. et al. Níveis de energia metabolizável para tambaqui (Colossoma macropomum) dos 30 aos 180 gramas de peso vivo. 1. Composição das carcaças. Revista da Sociedade Brasileira de Zootecnia, v.27, p.409-415, 1998.

CARNEIRO, D.J. Efeito da temperatura na exigência de protéina e energia em dietas para alevinos de pacu, Piaractus mesopotamicus (Holmberg, 1887). São Carlos: UFSCar, 1990. Tese (Doutorado em Ecologia e Recursos Naturais) - Universidade Federal de São Carlos, 1990.

CARNEIRO, D.J.; BARBOSA, N.D.; VIDOTTI, R.M. et al. Protein levels and animal origin protein proportion in piracanjuba diet (Brycon orbignyanus). In: SIMPÓSIO BRASILEIRO DE AQÜICULTURA, 10., 1998, Recife. Resumos/Abstracts ... Recife: Associação Brasileira de Aqüicultura, 1998. p.45.

CAVAlCANTI, C.A. Proteases digestivas em juvenis de piracanjuba (Brycon orbignyanus Eigenmann, 1909) e aplicação da técnica de digestibilidade "in vitro". Florianópolis: Universidade Federal de Santa Catarina, 1998. 101p. Dissertação (Mestrado em Aqüicultura) - Universidade Federal de Santa Catarina, 1998.

CHO, C.Y.; KAUSHIK, S.J. Effects of protein intake on metabolizable and net energy values of fish diets. In: COWEY, C.B.; MACKIE, A.M.; BELL, J.G. (Eds.) Nutrition and feeding in fish. London: Academic Press, 1985. p.95-117.

CLARK, A.E.; WATANABE, W.O.; OLLA, B.L. et al. Growth, feed conversion and protein utilization of Florida red tilapia fed isocaloric diets with different protein levels in seawater pools. Aquaculture, v.88, p.75-85, 1990.

COWEY, C.B.; SARGENT, J.R. Fish nutrition. In: OSLAGE, H.J.; ROHR, K. (Eds.) Fish physiology, London: Academic Press, 1979. v.8, p.1-69.

COWEY, C.B. Nutrition: estimating requirements of rainbow trout. Aquaculture, v.100, p.177-189, 1992.

DABROWSKI, K. Protein requirements of grass carp fry Ctenopharyngodon idella Val. Aquaculture, v.12, p.63-73, 1997.

DE SILVA, S.S.; PERERA, M.K. Effects of dietary protein levels on growth, food conversion and protein use in young Tilapia nilotica at four salinities. Transactions of the American Fisheries Society, v.114, p.584-589, 1985.

DING, L. Grass carp, Ctenopharyngodon idella. In: WILSON, R.P. (Ed.) Handbook of nutrient requirements of finfish. Boca Raton: CRC Press, 1991. p.89-96.

ECKMANN, R. Growth and body composition of juvenile Colossoma macropomum Cuvier 1818 (Characoidei) feeding on artificial diets. Aquaculture, v.64, p.293-303, 1991.

ELLIS, S.C.; REIGH, R.C. Effects of dietary lipid and carbohydrate levels on growth and body composition of juvenile red drum (Sciaenops ocellatus). Aquaculture, v.97, p.383-394, 1991.

EL-SAYED, A.M.; TESHIMA, S. Protein and energy requirements of Nile tilapia, Oreochromis niloticus, fry. Aquaculture, v.103, p.55-63, 1992.

FERNANDES, J.B.K. Fontes e níveis de proteína bruta em dietas para alevinos e juvenis de pacu, Piaractus mesopotamicus (Holmberg, 1887). Jaboticabal: UNESP, 1998. Tese (Doutorado em Aqüicultura) - Universidade Estadual Paulista, 1998.

FRACALOSSI, D.M.; ALLEN, M.E.; NICHOLS, D.K. et al. Oscars, Astronotus ocellatus, have a dietary requirement for vitamin C. Journal of Nutrition, v.128, p.1745-1751, 1998. 
GARLING Jr., D.L.; WILSON, R.P. Optimum dietary protein to energy ratio for channel catfish fingerlings, Ictalurus punctatus. Journal of Nutrition, v.106, p.1368-1375, 1976.

GODOY, M.P. Peixes e pesca do Rio Paraná: área do futuro reservatório de Ilha Grande. Florianópolis: ELETROSUL, 1986.

GUTIERREZ, W.;ZALDIVAR, J.; DEZA, S. et al. Determinacion de los requerimientos de proteina y energia de juveniles de paco, Piaractus brachypomus (Pisces, Characidae). Folia Amazonica, v.9, n.2, p.35-45, 1996.

HALVER, J. The nutritional requirements of cultivated warmwater and coldwater fish species. In: FAO TECHNICAL CONFERENCE ON AQUACULTURE, 1976, Kyoto. Proceedings... Kyoto, 1976. 9p.

HARDY, R.W.; MASUMOTO, T. Specifications for marine byproducts for aquaculture. In: INTERNATIONAL CONFERENCE ON FISH BY-PRODUCTS, 1991. Proceedings... Singapura: ASA, 1991. p.99-108.

HENKEN, A.M.; MACHIELS, M.A.M.; DEKKER, W. et al. The effect of dietary protein and energy content on growth rate and feed utilization of the african catfish Clarias gariepinus (Burchell 1822). Aquaculture, v.58, p.55-74, 1986.

JANTRAROTAI, W.; SITASIT, P.; JANTRAROTAI, P. et al. Protein and energy levels for maximum growth, diet utilization, yield of edible flesh and protein sparing of hybrid Clarias catfish (Clarias macrocephalus x C. gariepinus). Journal of World Aquaculture Society, v.29, n.3, p.281-289, 1998.

JAUNCEY, K. The effects of varying dietary protein level on the growth, food conversion, protein utilization and body composition of juvenile tilapia (Sarotherodon mossambicus). Aquaculture, v.27, p.43-54, 1982.

KAUSHIK, S. J., OLIVA-TELES, A. Effect of digestible energy on nitrogen and energy balance in rainbow trout. Aquaculture, v.50, p.89-101, 1986.

LEE, D.J.; PUTNAM, G.B. The response of rainbow trout to varying protein/energy ration in a test diets. Journal of Nutrition, v.103, p.916-922, 1973.

LOCHMANN, R.T., PHILLIPS, H. Dietary protein requirement of juvenile golden shiners (Notemigonus crysoleucas) and goldfish (Carassius auratus) in aquaria. Aquaculture, v.128, p.277-285, 1994.

LOVELL, T. Nutrition and feeding of fish. New York: Van Nostrand Reinhold, 1989. p.11-18.

MAZID, M.A.; TANAKA, Y.; KATAYAMA, T. et al. Growth response of Tilapia zilli fingerlings fed isocaloric diets with variable protein levels. Aquaculture, v.18, p.115-122.

MAYNARD, L.A.; LOOSLI, J.K.; HINTZ, H.F. et al. Animal nutrition. 7.ed. New York: McGraw-Hill, 1979. 602p.

MOORE, B.J.; HUNG, S.S.O.; MEDRANO, J.F. Protein requirement of hatchery-produced juvenile white sturgeon (Acipensertransmontanus). Aquaculture, v.71, p.235-245, 1988.

MEROLA, N.; CANTELMO, O.A. Growth, feed conversion and mortality of cage-reared tambaqui, Colossoma macropomum, fed various dietary feeding regimes and protein levels. Aquaculture, v.66, p.223-233, 1987.

NATIONAL RESEARCH COUNCIL - NRC. Nutrient requirements of fish. Washington, D.C.: 1993. 114p.
OJAVEER, H.; MORRIS, P.C.; DAVIES, S.J. et al. The response of thick-lipped grey mullet, Chelon labrosus (Risso), to diets of varied protein-to-energy ratio. Aquaculture Research, v.27, p.603-612, 1996.

PAGE, J.W.; ANDREWS, J.W. Interaction of dietary levels of protein and energy on Channel catfish (Ictalurus punctatus). Journal of Nutrition, v.103, p.1339-1346, 1973.

ROBBINS, K.R.; NORTON, H.W.; BAKER, D.H. Estimation of nutrient requirement from growth data. Journal of Nutrition, v.109, p.1710-1714, 1979.

ROBINSON, E.H.; WILSON, R.P. Nutrition and feeding. In: TUCKER, C.S. (Ed.) Channel catfish culture. New York: Elsevier, 1985. p.323-404.

SANTIAGO, C.B.; REYES, O.S. Optimum dietary protein level for growth of bighead carp (Aristichthys nobilis) fry in a static water system. Aquaculture, v.93, p.155-165, 1991.

SERRANO, J.A.; NEMATIPOUR, G.R.; GATLIN III, D.M. Dietary protein 0requirement of the red drum (Sciaenops ocellatus) and relative use of dietary carbohydrate and lipid. Aquaculture, v.101, p.283-291, 1992.

SHIAU, S.Y.; HUANG, S.L. Optimal dietary protein level for hybrid tilapia (Oreochromis niloticus x O. aureus) reared in seawater. Aquaculture, v.81, p.119-127, 1989.

SHIAU, S.Y.; LAN, C.W. Optimum dietary protein level and protein to energy ratio for growth of grouper (Epinephelus malabaricus). Aquaculture, 145:259-266, 1996.

SHYONG, W.J.; HUANG, C.H.; CHEN, H.C. Effects of dietary protein concentration on growth and muscle composition of juvenile Zacco barbata. Aquaculture, v.167, p.35-42, 1998.

SIDDIQUI, A.Q.; HOWLANDER, M.S.; ADAM, A.A. Effects of dietary protein levels on growth, feed conversion and protein utilization in fry and young Nile Tilapia, Oreochromis niloticus. Aquaculture, 70:63-73, 1988.

STICKNEY, R.R. Principles of aquaculture. New York: John Wiley, 1994. 502p.

TAKEUCHI, T.; WATANABE, T.; OGINO, C. Optimum ratio of dietary energy to protein for carpa. Bulletin of the Japanese Society of Science and Fisheries, v.45, p.983-987, 1979.

WINFREE, R.A.; STICKNEY, R.R. Effects of dietary protein and energy on growth, feed conversion efficiency and body composition of Tilapia aurea. Journal of Nutrition, v.111, p.1001-1012, 1981.
Recebido em: $14 / 03 / 01$ Aceito em: 06/09/01 